\title{
Evolution of energy metabolism, stem cells and cancer stem cells: how the Warburg and Barker hypothesis might be linked
}

\author{
James E Trosko \\ From São Paulo Advanced School of Comparative Oncology \\ Águas de São Pedro, Brazil. 30 September - 6 October 2012
}

Two explanations for the origin of cancers exist: the "Stem Cell Theory" [1-4] or the "De-Differentiation" or "Reprogramming Theory"[5]. Concepts related to the genesis of cancers include: (a) The Multi-Stage, Multi-Mechanism concept of carcinogenesis [6]; (b) the evolution of earth's physical environment ultimately allowed the appearance of anaerobic microbiological life forms that metabolized via glycolysis [7]; (b) the evolution of photosynthetic algae led to the oxygenation of the environment and to protoeukaryotes after the symbiotic marriage of bacteria that could produce energy via oxidative phosphorylation; (d) the Warburg metabolism of cancers [8]; (e) the concept of "cancer stem cells" and "cancer non-stem cells"[9]; and (f) the Barker hypothesis (diseases later in life might be the result of in utero embryonic/fetal exposures to a variety of factors [10]). To prevent and treat cancer, one must understand the complex mechanism of the multi-stage, multi-mechanism process of human carcinogenesis [11]. Starting with the initiation step of transforming a normal cell to one that is unable to terminally differentiate, and the "promotion" phase which comes about by the clonal expansion of this single initiated cell. Promotion is brought about the reversible inhibition of gap junctional intercellular communication, caused by growth factors, inflammatory stimulation, compensatory hyperplasia, due to chronic irritation or cell death, and by the ability to resist apoptotic death. A single cell can, then, accrue enough genotypic and epigenetic alterations to acquire all the "hallmarks" [12] of an invasive and metastatic cancer cell (the "progression" phase). Two important questions arise from this concept of the initiation/promotion/ progression process of carcinogenesis, namely; "What is the

Correspondence: james.trosko@ht.msu.edu

Department Pediatrics/Human Development, College of Human Medicine, Michigan State University, East Lansing, Michigan 48824, USA cell that is the target cell for 'initiation'?", and "What are the underlying molecular mechanisms for each phase of carcinogenesis?" With the discovery of cancer- initiating cells within a tumor, the concept of "cancer stem cells" has been generated. Implicit in this concept is the idea that each tumor is a heterogeneous mixture of "cancer non-stem cells" and "cancer stem cells". The current paradigm is based on the assumption that a somatic mortal, differentiated cell can be de-differentiated or re-programmed to become immortal, allowing it to survive long enough to accrue additional mutations and epigenetic changes to become neoplastically-transformed. This paradigm is supported by observations in the stem cell field, where "induced pluripotent stem cells" ("iPS") can be isolated from primary in vitro cultures with various cocktails of embryonic "stemness" genes [13]. However, there is an alterative interpretation of the origin of these "iPS" cells, namely, they were selected adult stem cells in those primary cultures [9]. In addition, the isolation of "MUSE" cells from normal human skin has demonstrated that these rare cells in the skin are the "target cells" for the socalled "iPS" cells [14]. Normal human adult stem cells are naturally "immortal" until they are induced to terminally differentiate. Adult stem cells can be inhibited from "mortalizing" or to remain "immortal" [15]. Dramatic demonstration has shown that only normal human breast stem cells could be efficiently blocked from "mortalization" and then neoplastically-transformed. This observation strongly supports the stem cell hypothesis [16,17]. Individual genetic, gender, dietary, environmental, life style, medical, lifespan and cultural factors can affect each of these three phases of carcinogenesis [18-21]. Genetic predispositions, such as xeroderma pigmentosum, leading to UVinduced skin cancer and the experimental carcinogenesis studies and epidemiological findings that clearly show how 
diets, environmental chemicals (asbestos), drugs (DES; estrogens), life style factors (alcohol; cigarette smoking) can enhance the risk to various cancers. What is sometimes ignored are cultural factors, such as postponement of childbearing (early child bearing is a cancer risk reducer). Other cultural factors, e.g., reduced exercise and dramatically altered diets and nutrition, have been associated with an increased caloric intake and non-nutritional diets of processed foods. A collision of biological evolutionary with cultural evolution is occurring. This allows for increased caloric intake, change in eating habits, types of foods, and even the relationship of the biological evolutional symbiotic role of our gut microbiota to our gut biology [22]. This collision has been more pronounced with caloric over-abundance, dramatically less physical exercise, the eating of processed foods and less of the early human diet-related foods, more grilled red meat, eating at all hours of the day, the changing of our gut microbiota and dieting with supplements. Clearly, biological evolution does not work fast enough to keep up with cultural evolutionary changes that affect our diet and other life style changes (postponing marriage; living longer). While all those factors can influence any of the phases of the carcinogenic process, initiation can never be reduced to a zero risk. Every time any cell replicates, there is always a finite chance of a mutation/initiation event to occur. The longer we live, the more initiated cells we accumulate. Except for teratomas, and early childhood cancers, most adult cancers take decades for the promotion process to expand the numbers of initiated cells for more mutational and epigenetic events to occur. Therefore, the promotion phase is the most efficacious period to intervene to prevent many cancers associated with environmental, dietary, life style, exercise and other cultural factors. One of the newer concepts that might also influence our understanding of risk factors to cancers is the "Barker hypothesis". Indirect experimental studies, as well as epidemiological studies, suggest that modulation (increased or decreased) of organ-specific adult stem cells could increase or decrease the risks to organ-specific cancers later in life ( e.g., DESexposed female fetuses led to vaginal cancers in young women; soy- and caloric- restricted female fetuses of Japanese women have been associated with low breast cancer frequencies of woman later in life) [22]. Two factors could reduce the risks to various cancers, namely, modulating stem cell numbers in utero by careful exposures to environmental/life style and nutritional factors (decrease the target size of 'initiation' step) and post-natally, by interfering with the "promotion" of initiated cells by those same factors.

\section{Competing interests}

There are no competing interests in this presentation.
Published: 4 April 2013

\section{References}

1. Till JE: Stem cells in differentiation and neoplasia. J Cell Physiol 1982, 1:3-11.

2. Pierce GP: Neoplasms, differentiation and mutations. Am J Pathol 1974, 77:103-118.

3. Markert C: Neoplasia: a disease of differentiation. Cancer Res 1968, 28:1908-1914.

4. Potter VR: Phenotypic diversity in experimental hepatomas: concept of partially blocked ontogeny. $\mathrm{Br} J$ Cancer 1978, 38:1-23.

5. Sell S: Cellular origin of cancer: differentiation or stem cell maturation arrest? Environ Health Perspect 1993, 101:15-26.

6. Weinstein IB, Cattoni-Celli S, Kirschmeier P, Lambert M, Hsiao W, Backer J, Jeffrey A: Multistage carcinogenesis involves multiple genes and multiple mechanisms. J Cell Physiol 1984, 3:127-137.

7. Saul JM, Schwartz L: Cancer as a consequence of the rising level of oxygen in the Precambrian. Lethaia 2007, 40:211-220.

8. Warburg O: On respiratory impairment in cancer cells. Science 1956, 124:269-270

9. Trosko JE: Cancer stem cells and cancer non-stem cells: from adult stem cells or from reprogramming of differentiated somatic cells. Vet Pathol 2009, 46:176-193.

10. Barker DJP: Mothers, babies, and health in later life. Churchill Livingstone, Edinburgh, UK i, 21998

11. Trosko JE, Tai MH: Adult stem cell theory of the multi-stage, multimechanism theory of carcinogenesis: role of inflammation on the promotion of initiated cells. In Infections and Inflammation: Impacts on Oncogenesis. Volume 13. S. Karger AG, Publisher;Dittmar, T, Zaenker, KS, Schmidt, A 2006:45-65, Contributions to Microbiology.

12. Hanahan D, Weinberg RA: Hallmarks of cancer: The next generation. Cell 2011, 144:646-674

13. Warren L, Manos PD, Ahfeld T, Lo YH, Li H, Lau F, Ebina W, Mandal PK, Smith ZD, Meissner A, Daley GQ, Brack AS, Collins JJ, Cowan C, Schlaeger TM, Rossi DJ: Highly efficient reprogramming to pluripotency and directed differentiation of human cells with synthetic modified mRNA. Cell Stem Cell 2010, 7:1-13.

14. Wakao S, Kitada M, Kuroda Y, Shigemoto T, Matsuse D, Akashi H, Tanimura Y, Tschiyama K, Kikuchi T, Goda M, Nakahata T, Fujiyoshi Y, Dezawa M: Multilineage -differentiating stress-enduring( MUSE) cells are a primary source of induced pluripotent stem cells in human fibroblasts. Proc Natl Acad Sci USA 2011, 108:9875-9880.

15. Trosko JE: Human adult stem cells as targets for cancer stem cells: Evolution, Oct-4 gene and cell-cell communication. In Cancer Stem Cells. Nova Science Publishers, Inc.:M.E. Jordon 2010:141-181.

16. Chang CC: Recent translational research: stem cells as the root of breast cancer. Breast Cancer Res 2006, 8:103-105.

17. Tai MH, Chang CC, Kiupel M, Webster J, Olson KA, Trosko JE: Oct-4 expression in adult stem cells: Evidence in support of the stem cell theory of carcinogenesis. Carcinogenesis 2005, 26:495-502.

18. Trosko JE: Pre-natal Epigenetic influences on acute and chronic diseases later in life, such as cancer: Global health crises resulting from a collision of biological and cultural evolution. J Food Science \& Nutrition 2011, 16:394-407.

19. Trosko JE: Stem cells and cell-cell communication in the understanding of the role of diet and nutrients in human diseases. J Food Hygiene \& Safety 2007, 22:1-14

20. Trosko JE: The gap junction as a 'Biological Rosetta Stone': Implications of evolution, stem cells to homeostatic regulation of health and disease in the Barker Hypothesis. J Cell Commun \& Signaling 2011, 5:53-66.

21. Gareau MG, Sherma PM, Walker WA: Probiotics and the gut microbiota in intestinal health and disease. Nature Rev/ Gastroenterology and Hepatology 2010, 503-514

22. Trosko JE: New concepts related to low level radiation induced carcinogenesis: Pre- and Postnatal modulation of adult stem cells modify the risks. In A New Challenge of Radiation Health Risk Management. Nagasaki Newsoaper Publish, Nagasaki, Japan;Nakashima, M., Takamura, N., Suzuki, K,m Yamashita,S 2012:75-91.

doi:10.1186/1753-6561-7-S2-K8

Cite this article as: Trosko: Evolution of energy metabolism, stem cells and cancer stem cells: how the Warburg and Barker hypothesis might be linked. BMC Proceedings 2013 7(Suppl 2):K8. 